\title{
Reduced-risk fungicides help manage brown rot and other fungal diseases of stone fruit
}

\author{
James E. Adaskaveg \\ Helga Förster \\ W. Doug Gubler \\ Beth L. Teviotdale \\ David F. Thompson \\ $\nabla$
}

New reduced-risk fungicides are highly effective in managing both pre- and postharvest diseases of stone fruit crops in California, and they have replaced most previously registered materials. These fungicides have a low impact on the environment, high specificity to target organisms, and low potential for groundwater contamination and human health risks. In stone fruit, they can be successfully used to manage brown rot blossom blight in a new delayed-bloom fungicide application program for lowprecipitation years. In our studies, we found that fungicide treatments applied 1 to 14 days before harvest were also effective against preharvest brown rot and protected fruit from fungal decays initiated during harvest. Practices such as mixtures and rotations can be implemented to prevent resistance from developing and to ensure the lasting efficacy of these reduced-risk fungicides.

IN 1996, the U.S. Congress unanimously passed the Food Quality Protection Act (FQPA). Among other things, the law formalized the U.S. Environmental Protection Agency's (EPA) Reduced-Risk Pesticide Program (initiated in 1993) and mandated that EPA continue to enhance it (EPA 2003, 2004). The FQPA expedited EPA's review and registration decision-making process for pesticides that are classified as less risky to human health and the environment than existing conventional products. The advantages of reduced-risk pesticides may include: low mammalian toxicity,

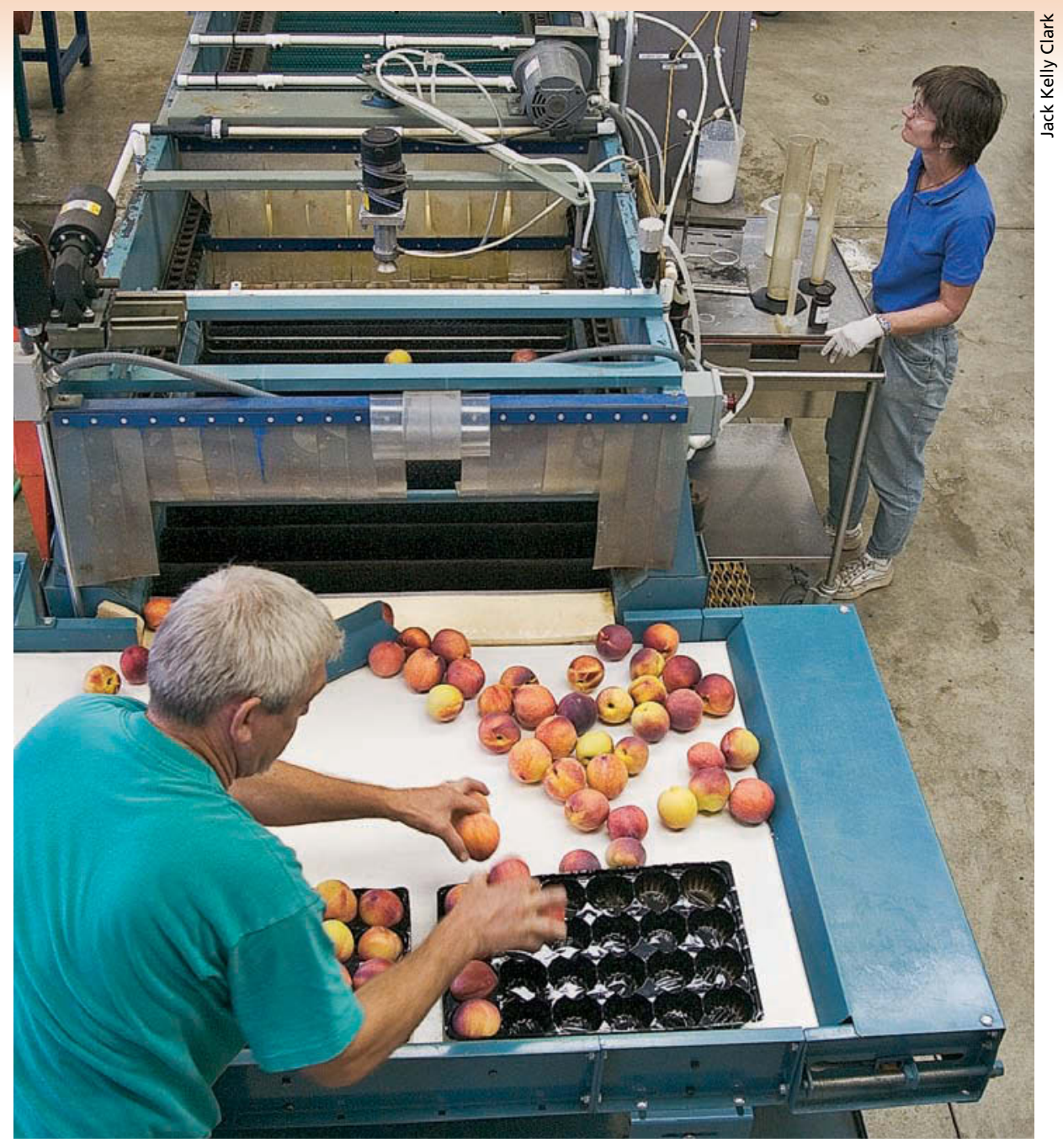

Project Scientist Helga Förster and Staff Research Associate George Driever run nectarines through an experimental packingline at the F. Gordon Mitchell Post Harvest Center at Kearney, to evaluate the performance of new reduced-risk fungicides under realistic postharvest conditions.

and in turn fewer risks to human health; low toxicity to nontarget organisms (such as bees, birds, fish and plants); low potential for groundwater contamination; low use rates; and compatibility with integrated pest management (IPM) practices (Adaskaveg et al. 2002).

Concurrently, agrochemical companies were on the verge of developing a plethora of new fungicides and fungicide classes, many of which qualified for reduced-risk status. The simultaneous development of these new fungicides by several manufacturers was unparalleled in the history of fungicide or other pesticide discovery and registration (Hewitt 1998; Uesugi 1998).

At the same time, however, the ongoing reregistration of older fungicides and other pesticides - mandated by Congress with amendments to the Federal Insecticide, Fungicide, and Rodenticide Act (FIFRA) in 1988 - made it financially prohibitive for agrochemical companies to reregister fungicides in the low-profit postharvest market. Postharvest fungicides that were not reregistered after 1996 included benomyl (Benlate), thiophanate-methyl (Topsin$\mathrm{M})$, triforine (Funginex) and iprodione 


\section{Infections of wounds that occur in the field at harvest are effectively stopped by postharvest treatments, typically done the same day.}

(Rovral). Our research goal at the UC Kearney Research and Extension Center (KREC) was to evaluate new reducedrisk fungicides for potential pre- and postharvest use on stone fruit crops, in order to proactively identify effective new fungicides and change the way they can be used.

The most important preharvest blossom and fruit disease of stone fruit crops in California is brown rot caused by Monilinia fructicola and M. laxa (Ogawa and English 1991). On freshmarket peaches, plums and nectarines, $M$. fructicola is the primary cause of blossom blight and pre- and postharvest fruit decay. Other diseases caused by the brown rot fungi include green shoot and mature shoot blights. Shoot blights, however, only occur in very wet environments and with high inoculum levels. Gray mold caused by Botrytis cinerea and Rhizopus rot caused by Rhizopus stolonifer also result in postharvest fruit losses every year. Thus, all three of these postharvest decays reduce crop yields and render commodities unmarketable (Eckert and Ogawa 1988).

Our trials with reduced-risk fungicides at KREC focused on these diseases. This work was done in cooperation with fungicide manufacturers and state and federal regulatory agencies including the Interregional Research Project No. 4 (IR-4 Project), which conducts residue studies for determining tolerances or maximum residues on "specialty" or "minor-use" crops (generally, those grown on 300,000 acres or less nationwide) such as stone fruit.

Several reduced-risk fungicides were included that have extremely low mammalian toxicity $\left(\mathrm{LD}_{50}\right.$ values from 2,000 to more than 5,000 milligrams per kilogram $[\mathrm{mg} / \mathrm{kg}]$ ) and are not known or suspected as carcinogens (table 1). These materials are either derivatives of naturally occurring compounds (such as fludioxonil [Scholar] and pyraclostrobin [Cabrio]) or were discovered by random chemical synthesis and screening for biological activity (such as boscalid [Endura], fenhexamid [Elevate] and pyrimethanil [Scala or Penbotec]). We evaluated cyprodinil (Vangard), fenhexamid, pyrimethanil and the premixture of boscalid and pyraclostrobin (Pristine) in preharvest studies, and fludioxonil and all the other compounds except cyprodinil in postharvest studies.

For all data reported in the figures, values followed by the same number are not significantly different based on an analysis of variance and LSD meanseparation procedures of SAS version 8.2.

\section{Brown rot blossom blight management}

While brown rot-infected blossoms on the tree rarely reduce crop load significantly, they are important inoculum

TABLE 1. Conventional and reduced-risk fungicides for management
of pre- and postharvest decays of stone fruit




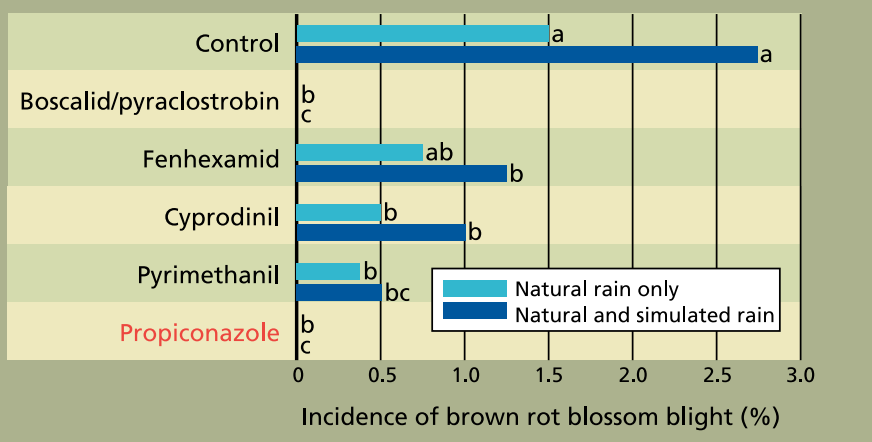

Fig. 1. Efficacy of reduced-risk, delayed-bloom fungicide applications for management of brown rot blossom blight in 'Elegant Lady' peaches with natural rain only ( 0.39 inches in 2003 and 0.79 inches in 2004), and natural rain plus simulated rain. Average of 2003 and 2004 data is shown. Conventional fungicide is shown in red type.

sources for fruit infections. The management of blossom blight involves integrating orchard sanitation with the judicious use of fungicides. Important sanitation practices include the removal of mummified fruit from trees and orchard floors after harvest as well as brown rot cankers during pruning. Previously, UC guidelines suggested a two-application program of fungicides at the phenological blossom stages of pink bud (5\% bloom) and full bloom ( $80 \%$ bloom). The current updated guidelines (www.ipm.ucdavis. edu/PHG) are based in part on the research presented here. They indicate that a delayed, $20 \%$ to $40 \%$ bloom treatment should be made followed by a second application at $80 \%$ to $100 \%$ bloom, if heavy rain or other weather conditions (such as dense fog and warm temperatures) are conducive to fungal diseases.

In 2003 and 2004, we compared the efficacy of the new reduced-risk fungicides with that of older fungicides (which generally require higher application rates) in a stone fruit orchard at KREC. A single delayed-bloom application (20\% to $40 \%$ full bloom) was done. Although blossom infections could have already occurred at this bloom stage, our intent was to evaluate the fungicides for their protective and postinfection activity. In addition to natural rain (0.39 inches in 2003 and 0.79 inches in 2004 during the 2-week bloom period when the trial was conducted), simulated rain was provided by two high-angle overhead sprinkler irrigations of 6 to 8 hours each, within 5 days after fungicide application. This was done to find out how treatments would perform under high rainfall and subsequent microclimate alterations associated with wet conditions such as high relative humidity — which may occur in California during wet springs.

Similar trends were obtained for all treatments in both years. With simulated rain, the reduced-risk materials were effective in reducing brown rot incidence as compared with the untreated control, but some of them were more effective under ambient conditions (natural rain only)(fig. 1). With boscalid/pyraclostrobin or propiconazole, no disease was found under simulated or natural rain conditions. In addition, in years (2001 and 2002) when natural rainfall was low during the bloom period, no disease was detected in any of the treatments evaluated in our trials, whereas in the control, $1.5 \%$ of the blossoms were diseased. Although this blossom blight incidence may seem low, it is a moderate disease level considering the amount of new inoculum that can be produced to contaminate developing fruit in the current growing season. The reduced-risk fungicides performed as well as the conventional products tested, and one application was enough to reduce brown rot pressure in years when conditions were less conducive to disease.

\section{Preharvest treatments}

In California's semiarid climate, brown rot fruit decay before harvest is generally less severe than postharvest decay of untreated fruit, unless the fruit are mature and rain occurs at harvest time (similar to stone fruit production in high rainfall regions) or improper irrigation practices create favorable environments for disease. Decay may develop from conidia (spores) contaminating fruit surfaces or from recent infections or quiescent (latent) infections that occur with brown rot and gray mold. Inoculum from mummified fruit, twig cankers or blighted blossoms commonly contaminates fruit surfaces during the growing season. Quiescent infections (in which the fungus enters plant tissue but does not continue to grow or cause disease until later) are initiated much earlier in the season. Growth of the pathogen, however, does not continue because fruit are immature and resistant to fungal decay. As fruit ripen, rapid decay may result before or after harvest even when environmental conditions at harvest time are not conducive to infection. Still, quiescent infections are considered only a minor cause of fruit decay in most years (Emery et al. 2000).

In general, preharvest fungicide treatments reduce inoculum (preventing infections that later sporulate or inhibiting sporulation of existing infections) or prevent quiescent and active infections on 
fruit before harvest. Furthermore, these treatments can protect against wound infections that occur during harvesting operations. Fruit injuries may occur from contact with plant debris, soil particles or equipment surfaces, or from improper handling by harvesters. Preharvest fungicide treatments can reduce the incidence of postharvest fruit decay, which is especially important when fruit is exported to countries that do not allow the use of postharvest fungicides.

In all of our evaluations we tried to simulate standard commercial fruithandling practices as closely as possible. In general, stone fruit are harvested, stored and shipped at low temperatures, and then marketed in grocery stores and ripened by consumers at ambient temperatures. Preharvest fungicide applications were evaluated over several seasons from 2001 to 2003 in 'Red Diamond' nectarine and 'Elegant Lady' peach orchards at KREC. Treatments were made at 14 days and 1 day before harvest, or at 7 days and 1 day before harvest, using an air-blast sprayer calibrated for 100 gallons per acre on four or five single-tree replications for each treatment in a randomized plot. Harvested fruit were evaluated either for the natural incidence of decay or for decay protection, after we manually wounded and inoculated the fruit with decay pathogens. For both evaluations, harvested fruit were refrigerated for 1 week at $33^{\circ} \mathrm{F}$ to $37^{\circ} \mathrm{F}$ and then transferred to an incubation room maintained at $68^{\circ} \mathrm{F}$ (approximately room temperature). Fruit were wounded (using a small, beveled-edged nail that simulated a fingernail scratch) and inoculated with conidia of the brown rot fungus (M. fructicola) or gray mold fungus (B. cinerea).

In our studies, brown rot was the main natural decay that developed on the incubated fruit. On both stone fruit cultivars, all fungicides evaluated significantly reduced the incidence of decay (fig. 2), including the sterol biosynthesis inhibiting (SBI) fungicides (propiconazole and tebuconazole) and the reduced-risk materials (boscalid/ pyraclostrobin, fenhexamid, cyprodinil and pyrimethanil). Decay incidence after wound inoculations on unwashed fruit was also significantly reduced by all treatments for both brown rot and gray mold (fig. 3A), but the efficacy

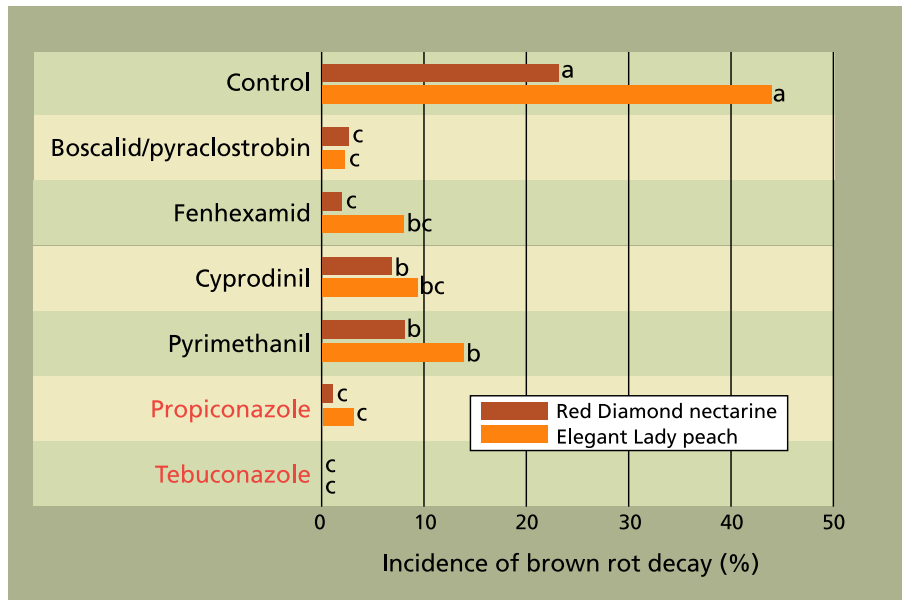

Fig. 2. Efficacy of reduced-risk preharvest fungicides to manage natural incidence of brown rot fruit decay. Treatments were applied using an air-blast sprayer (100 gal/acre) at 14 days and 1 day before harvest for 'Red Diamond' nectarines, and at 7 days and 1 day before harvest for 'Elegant Lady' peaches. Conventional fungicides are shown in red type. materials was generally lower than in our studies on the natural incidence of decay.

In additional studies, preharvesttreated fruit were washed postharvest over a brush bed on an experimental packingline using chlorine water (100 parts per million [ppm] sodium hypochlorite), rinsed with plain water and treated with a postharvest fruit coating, again similar to commercial practices, and fruit were then wound-inoculated. This washing step further reduced the efficacy of the reduced-risk materials against brown rot decay, and this was correlated with a reduction of fungicide residues in fruit. In contrast, the SBI fungicide treatment (tebuconazole) was still highly active against brown rot. However, cyprodinil and pyrimethanil were still very effective against gray mold decay (fig. 3B).

These studies on preharvest fungicide applications demonstrated several characteristics of the new group of fungicides. First, some of the new fungicides - particularly boscalid / pyraclostrobin - performed as well as the SBI materials for managing natural decay. SBI fungicides set the standard for effective preharvest treatments of stone fruit after iprodione was cancelled for preharvest use in 1998. In addition, the new reduced-risk materials generally were less effective when fruit were wounded after treatments, indicating that there is little penetration into the fruit and

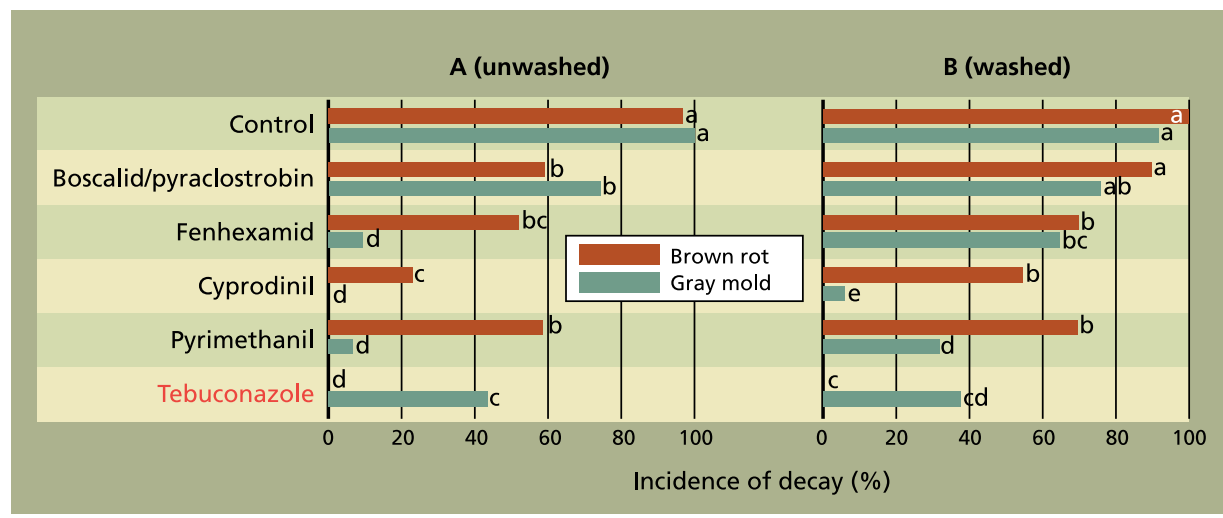

Fig. 3. Efficacy of reduced-risk preharvest fungicide applications for management of brown rot and gray mold fruit decay in 'Elegant Lady' peaches after wound inoculation. Treatments were applied using an air-blast sprayer (100 gal/acre) at 7 days and 1 day before harvest. After harvest, fruit were left (A) unwashed or (B) washed, and waxed on an experimental packingline and wound-inoculated with conidia of either decay fungus. Conventional fungicide is shown in red type. 


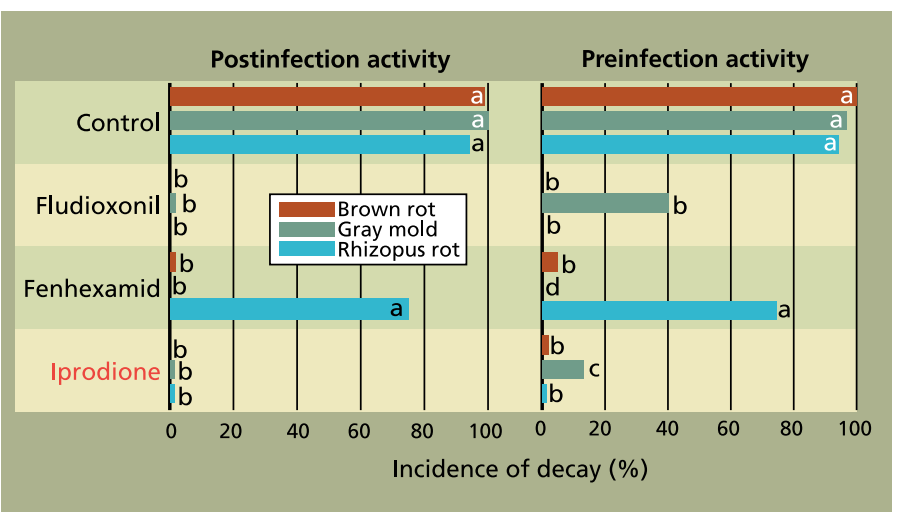

Fig. 4. Efficacy of reduced-risk postharvest fungicide applications to manage fruit decays of 'Red Diamond' nectarines. Treatments (postinfection, 12 to 14 hours after inoculation; and preinfection, before inoculation) were done in a diluted emulsified mineral oilbased fruit coating using a low-volume controlled droplet applicator (for rates, see table 1). Conventional fungicide is shown in red type.

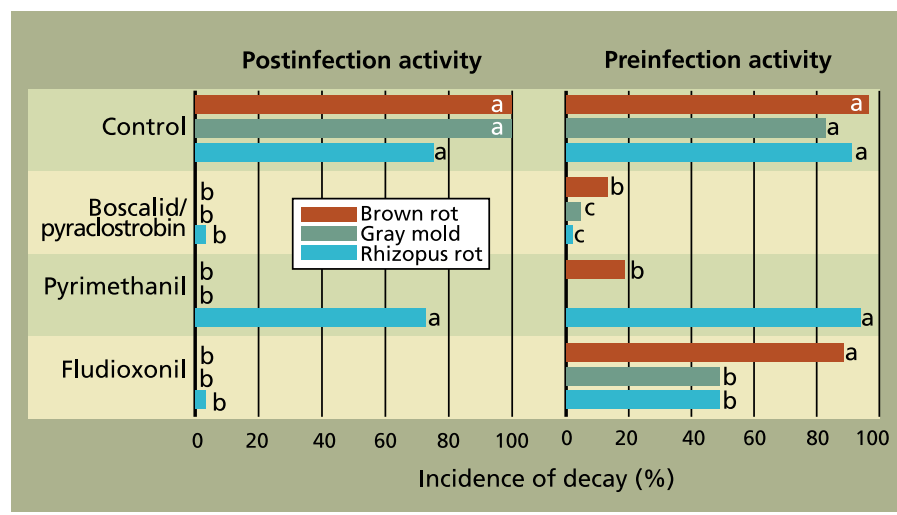

Fig. 5. Efficacy of reduced-risk postharvest fungicide applications to manage fruit decays of 'Red Diamond' nectarines. Treatments (postinfection, 12 to 14 hours after inoculation; and preinfection, before inoculation) were done in a diluted emulsified mineral oil-based fruit coating using a high-volume T-jet application system (for rates, see table 1 ). demonstrating that these materials are mainly wound-protectants.

Furthermore, fungicide residues on the fruit surface can be removed to a large degree by washing, as shown by the reduced decay control that we found in our experiments (fig. 3). Although growers and packers find this less desirable, consumers want less pesticide residue on their fruit. Pesticides that have extremely low mammalian toxicity and are easily removed by washing will be more acceptable to the consumer than previously registered products.

\section{Postharvest fungicide applications}

Postharvest decay fungi infect stone fruit tissue through wounds that occur either before harvest or,

TABLE 2. Efficacy (+++ = most effective to - = ineffective) of conventional and reducedrisk postharvest fungicides as wound-protection treatments of stone fruit

\begin{tabular}{|c|c|c|c|}
\hline Fungicide & $\begin{array}{c}\text { Brown } \\
\text { rot }\end{array}$ & $\begin{array}{l}\text { Gray } \\
\text { mold }\end{array}$ & $\begin{array}{l}\text { Rhizopus } \\
\text { rot }\end{array}$ \\
\hline
\end{tabular}

\section{Reduced risk}

Boscalid/

pyraclostrobin $\quad+++\quad+++\quad+++$

Fenhexamid

Fludioxonil

Pyrimethanil

Conventional

Dicloran

Iprodione*

Tebuconazole $\neq$

$++\quad+++$

$++$

$+++$

$-$

$++$

$++$

$+++$

$-$

* Iprodione was cancelled for postharvest use in 1996.

† Only highly effective against Rhizopus rot when used in a fruit coating.

‡ Only registered for use on sweet cherry. more importantly, during or after harvest. The main goals of a postharvest decay management program are to: avoid fruit injuries, keeping the fruit healthy and nonsenescent; remove pathogen inoculum from the surface by sanitation; inhibit the pathogen in infections that may occur at harvest; and protect the fruit from infections during postharvest handling, shipping and marketing. In wet years conducive to disease, a large portion of the crop may be destroyed by postharvest decay. Without a postharvest fungicide treatment, fruit usually cannot be shipped over long time periods (2 to 3 weeks) to distant markets or displayed in the market at shelf temperatures without decay developing, making it difficult to ensure that high-quality fruit reaches the consumer (Adaskaveg et al. 2002).

Postharvest fungicides were evaluated on an experimental packingline at KREC. This packingline includes a brush wash bed, a drying area with sponge rollers, and low- and high-volume fungicide application equipment over brush and roller beds. The setup is similar to commercial treatment systems, albeit downscaled. We determined the spectrum of activity of the fungicide treatments, as well as the optimum application methods and compatibilities with the most commonly used fruit coatings, which improve appearance and prevent water loss from healthy, ripening fruit.

Fruit were either: (A) inoculated, incubated for 14 hours at $68^{\circ} \mathrm{F}$, treated with fungicides and incubated for decay development at $68^{\circ} \mathrm{F}$; or (B) treated, inoculated and then incubated. These schedules were used to obtain information on the post- (such as wound protection) and preinfection activity of the fungicides, respectively. We evaluated the efficacy of the treatments as the incidence of decay compared with the untreated control.

To control brown rot and gray mold, fenhexamid, boscalid/pyraclostrobin, pyrimethanil and fludioxonil showed excellent activity as postinfection treatments, while fenhexamid and pyrimethanil were not effective against Rhizopus rot (figs. 4, 5). The efficacy of the fungicides as preinfection treatments was generally lower and inconsistent for fenhexamid, boscalid/pyraclostrobin and fludioxonil. These fungicides are mainly wound-protection treatments that are highly effective in preventing decay from infections when initiated up to 16 hours before treatment. Infections of wounds that occur in the field at harvest are effectively stopped by postharvest treatments, typically done the same day. Our data also indicates that the new reduced-risk fungicides, particularly boscalid/pyraclostrobin and fludioxonil, have a spectrum of activity and efficacy comparable to the cancelled iprodione (table 2). 


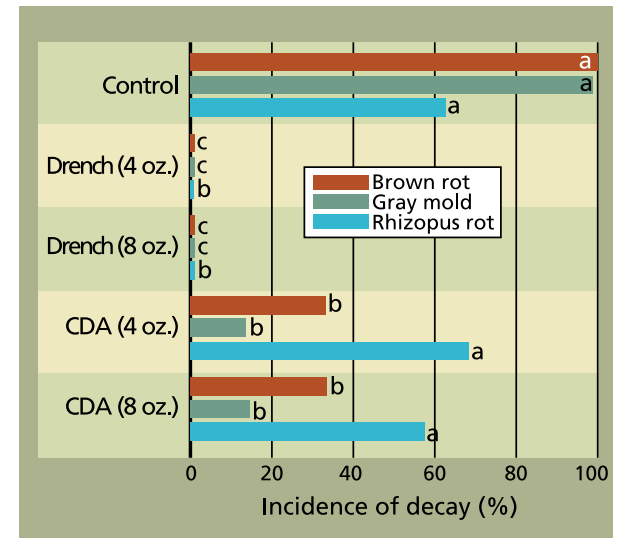

Fig. 6. Postinfection activity of fludioxonil treatment (14 to 16 hours after inoculation) to prevent fruit decays of 'Casselman' plums, with low-volume controlled droplet applications (CDA)(rate is per 10 gallons water, per 200,000 pounds fruit) on a roller bed, and drench applications in aqueous solutions (rates are per $\mathbf{1 0 0}$ gallons water per 200,000 pounds fruit) followed by CDA, both with diluted carnauba fruit coating.

\section{Application methods compared}

Postharvest application methods were evaluated to maximize fungicide efficacy and minimize disposal issues and costs. Among the application methods used commercially, low-volume and ultra-low-volume controlled droplet applications (CDA; 1 to 25 gallons of solution per 200,000 pounds of fruit) are currently the most popular because there is little or no fungicide runoff as compared with high-volume application methods (generally 100 gallons per 200,000 pounds of fruit). Fungicide runoff cannot be easily disposed of in the sewer systems of most municipalities. In peaches and nectarines, the low-volume fungicide treatment can be applied on a brush bed to the wet, washed fruit, dispersing it evenly over the surface. Treating smooth-skinned plums is more problematic because the waxy fruit surface often prevents sufficient uniform coverage. In addition, removal of the waxy bloom on plums by brushing may decrease their desirability in some markets.

As an alternative for plums, we evaluated recirculated, high-volume drench applications over a roller bed. Although this method uses a large volume of fungicide solution, any runoff is collected and recirculated for reuse. To prevent microbial contaminants from growing in the fungicide solution, a sanitizer must be added and the fruit must be thoroughly washed before treatment. Fludioxonil is particularly suited for this type of application because it is very stable in sodium hypochlorite solutions at 100 parts per million (ppm) active chlorine, while the recirculating application system makes this expensive material more cost-effective. In our studies, drench applications were significantly more effective wound-protection treatments than low-volume spray applications (fig. 6). In addition, we observed that fruit treated with aqueous fungicide drench applications over a roller bed followed by a CDA application with a carnauba-based fruit coating retained most of their natural bloom, for a higher market value.

\section{Resistance management is key}

Reduced-risk fungicides have an unparalleled safety profile and are equivalent or superior in their efficacy to previously and currently registered older fungicides for management of preand postharvest diseases in stone fruit. Cyprodinil, fenhexamid and boscalid/ pyraclostrobin are fully registered for preharvest use (table 1). Fludioxonil was registered for postharvest use on all stone fruit in 2003. Due to its lightsensitivity with degradation in ultraviolet light and nonpersistence in the environment, fludioxonil will not be considered for a preharvest registration.

Because the new materials belong to different chemical classes with modes of action different from the older fungicides, resistance management programs can be designed that are based on mixtures and rotations of materials (Kendall and Hollomon 1998). In addition, good stewardship of these single-site mode of action compounds should include proper application procedures (Adaskaveg and Forster 1999) that leave adequate fungicide residues on the fruit and the appropriate disposal of fungicide runoff and fungicide-treated culls. Reduced-risk fungicides will not completely replace the older fungicides in the near future, but safer chemical control options will be available in many situations. The most important role of the older materials will be their inclusion in resistance management programs with the newer products. With appropriate strategies, the new reduced-risk tools should be available for years to come.

J.E. Adaskaveg is Associate Professor, and H. Förster is Project Scientist, Department of Plant Pathology, UC Riverside; W.D. Gubler and B.L. Teviotdale (retired) are Cooperative Extension Specialists, Department of Plant Pathology, UC Davis; and D.F. Thompson is Staff Research Associate, UC Riverside. We gratefully acknowledge George Driever, Staff Research Associate, for his contributions to this study; and appreciate financial support from the California Tree Fruit Agreement and agrochemical companies (Arvesta, BASF, Bayer, Janssen Pharmaceutica and Syngenta Crop Protection).

\section{References}

Adaskaveg JE, Förster H. 1999. Fungicides and their stewardship in a new century of production agriculture. Nut Grower 19:5-7.

Adaskaveg JE, Förster H, Sommer NF. 2002. Principles of postharvest pathology and management of decays of edible horticultural crops. In: Kader A (ed.). Postharvest Technology of Horticultural Crops (4th ed.). UC DANR Pub 3311. Oakland, CA. p 163-95.

Eckert JW, Ogawa JM. 1988. The chemical control of postharvest diseases: Deciduous fruits, berries, vegetables and root/tuber crops. Ann Rev Phytopathol 26:433-69.

Emery KM, Michailides TJ, Scherm H. 2000. Incidence of latent infection of immature peach fruit by Monilinia fructicola and relationship to brown rot in Georgia. Plant Dis 84:853-7.

[EPA] US Environmental Protection Agency. 2004. The Food Quality Protection Act (FQPA) Background. www.epa.gov/oppfead1/fqpa/ backgrnd.htm (accessed 2/8/05).

EPA. 2003. Reducing Pesticide Risk. www. epa.gov/pesticides/controlling/reducedrisk. htm (accessed 2/8/05).

Hewitt HG. 1998. Fungicides in Crop Protection. New York: CAB Internat. 221 p.

Kendall SJ, Hollomon DW. 1998. Fungicide resistance. In: Hutson D, Miyamoto J (eds.). Fungicidal Activity-Chemical and Biological Approaches to Plant Protection. Chichester, Eng.: J Wiley. p 87-108.

Ogawa JM, English H. 1991. Diseases of Temperate Zone Tree Fruit and Nut Crops. UC DANR Pub 3345. Oakland, CA. 461 p.

Uesugi Y. 1998. Fungicide classes: Chemistry, uses and mode of action. In: Hutson D, Miyamoto J (eds.). Fungicidal Activity-

Chemical and Biological Approaches to Plant Protection. Chichester, Eng.: J Wiley. p 23-56. 